\title{
MASW Survey with Fixed Receiver Geometry and CMP Cross-Correlation Technique for Data Processing: A Case Study of Wadi Fatima, Western Saudi Arabia
}

\author{
Faisal Rehman1, Sherif M. El-Hady2,3, Muhammad Faisal4, Hussein M. Harbi2, \\ Muhammad Fahad Ullah', Saifur Rehman', Muhammad Kashif ${ }^{5}$ \\ ${ }^{1}$ Department of Earth Sciences, University of Sargodha, Sargodha, Pakistan \\ ${ }^{2}$ Department of Geophysics, Faculty of Earth Sciences, King Abdulaziz University, Jeddah, KSA \\ ${ }^{3}$ Earthquake Department, National Research Institute of Astronomy and Geophysics, Helwan, Egypt \\ ${ }^{4}$ Oil and Gas Development Company Limited, Islamabad, Pakistan \\ ${ }^{5}$ China University of Petroleum (East China), Qingdao, China \\ Email: Faisal.rehman@uos.edu.pk
}

How to cite this paper: Rehman, F., El-Hady, S.M., Faisal, M., Harbi, H.M., Ullah, M.F., Rehman, S. and Kashif, M. (2018) MASW Survey with Fixed Receiver Geometry and CMP Cross-Correlation Technique for Data Processing: A Case Study of Wadi Fatima, Western Saudi Arabia. Open Journal of Geology, 8, 463-473.

https://doi.org/10.4236/ojg.2018.85027

Received: February 16, 2018

Accepted: May 7, 2018

Published: May 10, 2018

Copyright $\odot 2018$ by authors and Scientific Research Publishing Inc. This work is licensed under the Creative Commons Attribution International License (CC BY 4.0).

http://creativecommons.org/licenses/by/4.0/

\section{(c) (i) Open Access}

\begin{abstract}
Multichannel analysis of surface waves is a noninvasive technique for subsurface shear wave velocity imagining. This method is one of the most effective geophysical tools for geotechnical investigations. In this paper, we present multichannel surface wave data acquisition in a non-conventional manner in alluvium deposits. Fixed receiver and multi-source offset geometry were applied to obtain field data. The data processing comprised of generating CMP cross-correlated traces and then inversion to obtain dispersion curves. The inversion of dispersion curves is achieved by employing a genetic algorithm to obtain subsurface shear wave velocity. Finally, the one-dimensional shear wave models are obtained. The multi-source offset data acquisition with fixed receiver geometry technique in combination with CMP cross-correlation gathers for data processing worked in a quite efficient way to obtain subsurface shear wave model.
\end{abstract}

\section{Keywords}

Shallow Geophysics, Noninvasive Technique, MASW, Shear Wave Velocity, Genetic Algorithm

\section{Introduction}

Near surface geophysical techniques and tools are more extensively applied in 
geological and geotechnical applications. The non invasive nature and rapid data acquisition in cost efficient manner make them an essentially necessary tool to invasive techniques. The multi channel analysis of surface waves (MASW) is one of the near surface geophysics techniques which have seen intensive applications in the geotechnical and engineering geology [1]. Multichannel analysis of surface waves (MASW) has been successfully applied in various shallow geophysical soundings [2]-[9]. MASW is a rapid and quick methodology to estimate the near surface shear wave velocity (Vs) and overcome more than a few shortcomings of other different techniques which lead to the false impression of phase velocities [10] [11] [12]. Fundamental mode of surface waves is often used, which comprised of the highest energy portion amongst all wave types [13].

The arrival time coherency difference is the base for identifying the ground roll on multichannel record. The confidence level on shear wave velocity estimation results can be increased using appropriate data processing methodology [14]. Each wavelength has typical velocity signature, named as phase velocity [15]. There is a fundamental assumption that approximately $92 \%$ of ground roll phase velocity is comprised subsurface shear wave velocity [16]. The Rayleigh waves or ground rolls can be produced with impact source like hammer and non impact source like vibrosis. The depth penetration of this type of waves in normal conditions is assumed approximately equal to its wavelength [17].

In current study, we applied fixed receiver geometry for MASW data acquisition in alluvial deposits. In conventional MASW technique, we need to move source and receiver positions for each shot. The current study is an attempt to explore the efficiency of fixed receiver geometry for data acquisition and CMP cross-correlation technique for data processing in alluvium deposits. The study area is located in Wadi Fatima, east of Jeddah city, Saudi Arabia (Figure 1). The Wadi Fatima is one of the distinctive foreland fold-thrust belts in the Arabian-Nubian Shield. The quaternary sediments are comprised of alluvial fillings and fan deposits [12] [18].

\section{Study Area}

The study area is located in the Wadi Fatima. The outcrops rock comprised of Neo-Proterozoic age in the study area. These outcrops (Figure 2) can be divided into two major lithological units: Fatima group and pre-Fatima basement. The outcrops of pre-Fatima basement include granites, amphibolites, gabbros, andesites and local rhyolitic intrusions. The Fatima group comprised of sedimentary rocks, volcanic rocks and lower greenschist facies. The Wadi fills comprised of moderate to poorly sorted, unconsolidated sand and gravels deposits of tertiary and quaternary age [19] [20]. The Wadi Fatima is a designated as graben structure, commonly termed as Fatima graben having major structural trend NE-SW. Many NW-SE faults dissect Fatima graben. These faults are linked with rifting at Red Sea [18] [21]. 


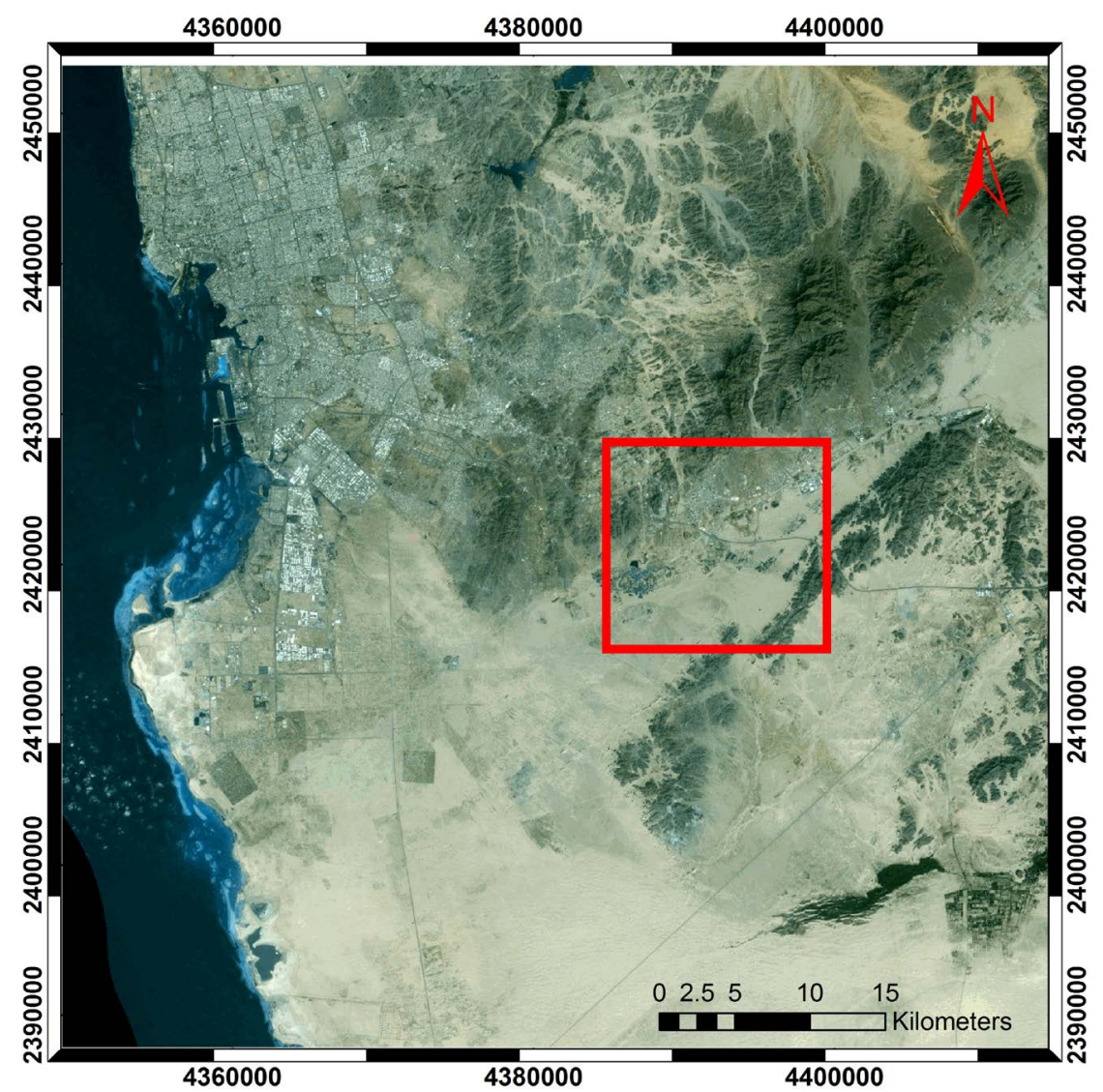

Figure 1. Location map with study area in the red box.

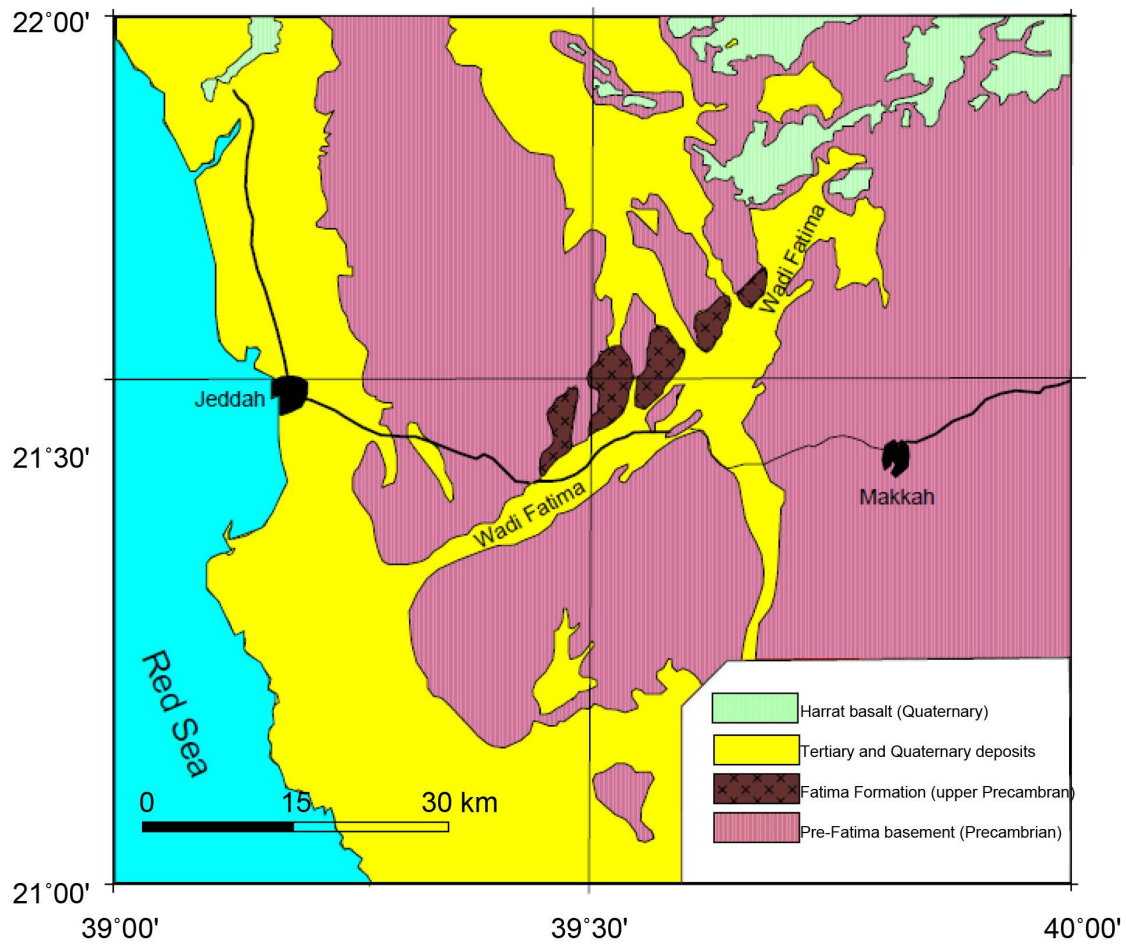

Figure 2. Geological map of study area (12). 


\section{Field Survey}

A long receiver array as possible is used in MASW method. Although, the lateral resolution of survey is compromised in longer array, the velocity model provided by the conventional MASW method is averaged over the total length of the spread. A smaller array is more suitable for enhancing lateral resolution [22]. The methodology to acquire data for current survey is similar to conventional MASW Data acquisition; however the receiver's position was kept fixed. The source offset was increased. The MASW data is collected in 24 points in the study area (Figure 3). The Geometrics System and 24 vertical geophones with $4.5 \mathrm{~Hz}$ frequency are employed to acquire surface wave data. A 16lb sledgehammer was employed as a source of seismic waves. The choice of seismic source which meets the project's goals and requirements has strong influence on project's efficiency in shallow seismic surveys. Seismic source selected should be efficient to produce strong signal having specific frequency response [23]. Different offset geometries were applied to acquire 24 MASW profiles summarized in Table 1. A land streamer was built for MASW survey with one meter geophone interval using flat metals base connected along flexible Irrigation pipe

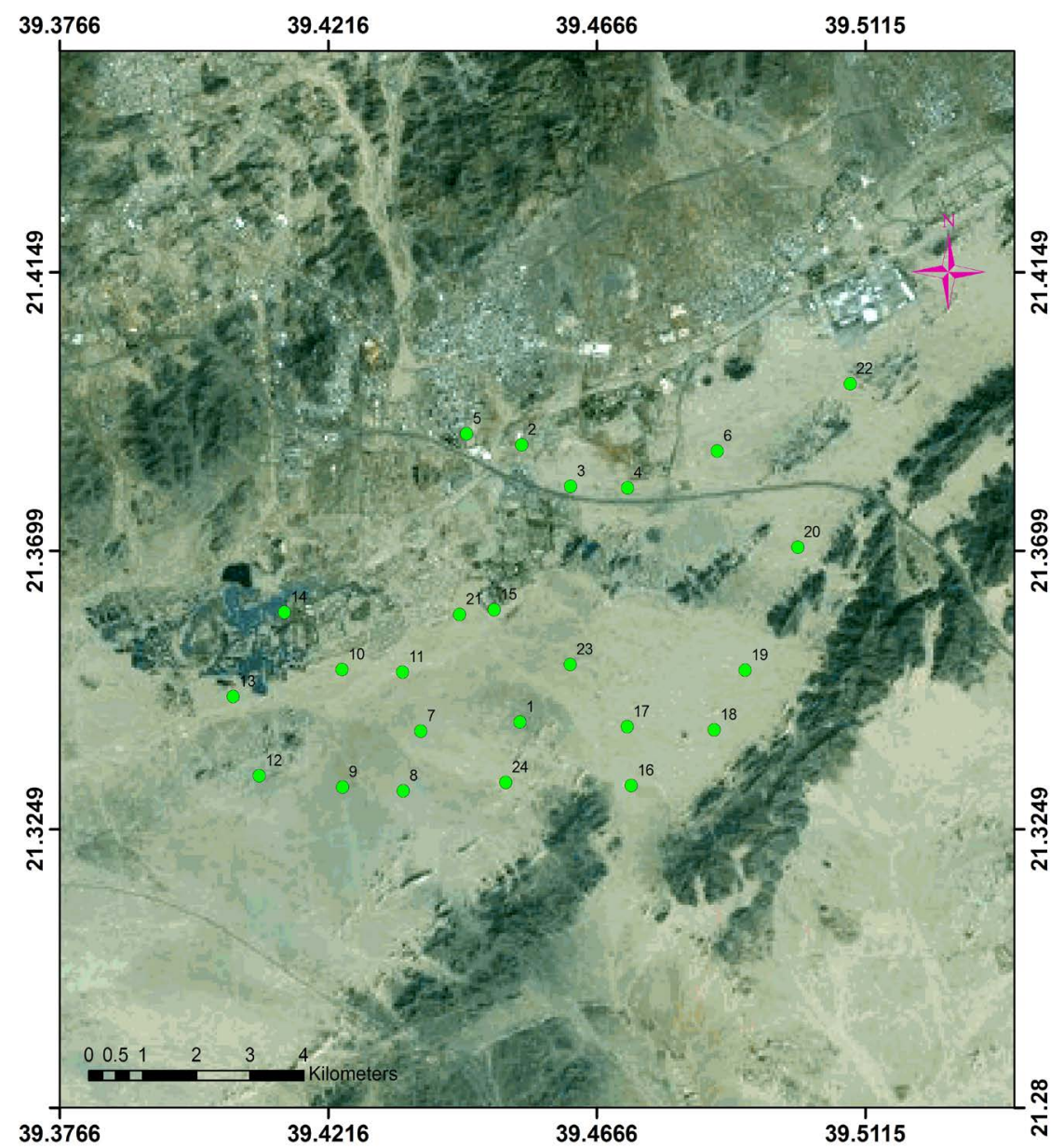

Figure 3. Location of MASW profiles across the Wadi Fatima in the study area. 
Table 1. Description of various offset geometries with number of profiles acquired.

\begin{tabular}{ccc}
\hline Sr. No & Shot Locations & No of Profiles \\
\hline $\mathbf{1}$ & $-10,11.5,33$ & 1 \\
2 & $-10,-5,11.5,28,33$ & 1 \\
$\mathbf{3}$ & $-12,-6,11.5,29,37$ & 1 \\
$\mathbf{4}$ & $-12,-6,11.5,29,35$ & 3 \\
$\mathbf{5}$ & $-24,-12,-6,29,35,47$ & 8 \\
$\mathbf{6}$ & $-24,-12,-6,29,35$ & 1 \\
7 & $-30,-24,-12,-6,29,35,47,53$ & 5 \\
$\mathbf{8}$ & $-30,-24,-12,-6,29,35,47,53,59$ & 1 \\
9 & $-42,-24,-12,-6,29,35,47,65$ & 3 \\
& Total Profiles Acquired & 24 \\
\hline
\end{tabular}

(PVC HDPE). The amplitude of surface-wave energy acquired in MASW is several times larger than body wave's energy which is recorded in other seismic waves methods. Thus, pressure contact geophones can be utilized to record surface wave instead of the normally planted geophones. Pressure coupling actually permits the use of towable "land streamers" for MASW surveys, which results in continuous data acquisition. The efficiency of data acquisition is increased greatly as compared to traditional body wave seismic methods [24].

Figures 4(a)-(c) are a field photographs demonstrating the procedure adopted for MASW data acquisition. It started with laying down the streamer along the location of surveyed profile, assigning the shots locations using zero distance from first channel (Table 1). Each shot location comprised of 5 stacks recorded in a single file in the recording unit (Figure 4(b)). After finishing the acquisition for all shots, the streamer was dragged by car to next location (Figure 4(c)). The major objective is to test various offset geometries in different alluvial deposits and the effectiveness of cross-correlation CMP gathers processing technique in this environment.

\section{Data Processing and Results}

The Common Midpoint (CMP) cross-correlation gathers for MASW data is a known technique with good estimation and accuracy of phase velocity. The CMP stacked gathers are utilized to obtain surface wave dispersion curve [22] [25] [26] [27]. The most vital step is shear wave's velocity reconstruction in 1D by means of dispersion curve inversion [28] [29]. The inversion can be achieved by many methods like Genetic Algorithms [30] and/or least-squares approach [31].

\subsection{Common Mid-Point Cross-Correlation (CMPCC)}

In case of MASW, the surface wave analysis package of SeisImager 4.2 version is utilized for data processing and inversion. Common mid-point (CMP) cross- 


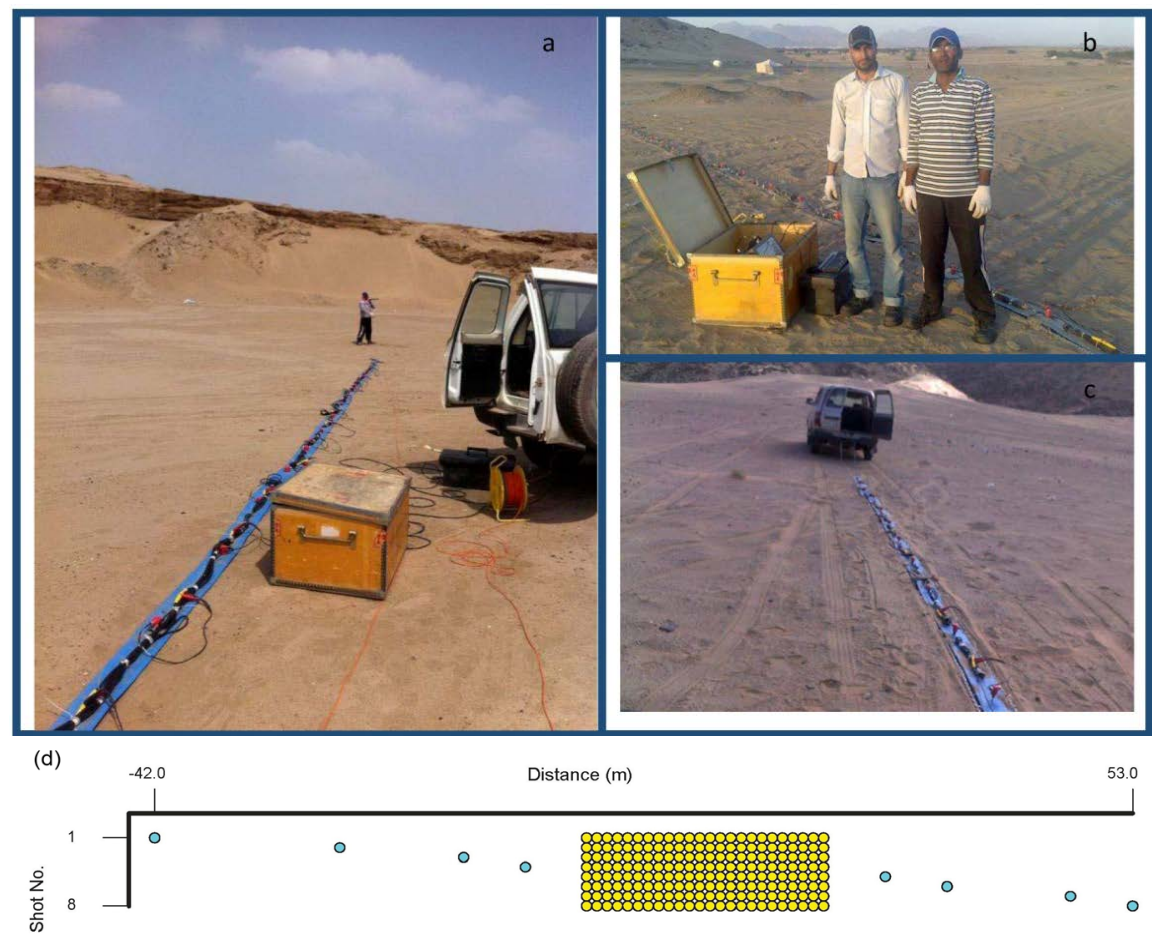

Figure 4. Field procedure for MASW data acquisition (a) Assigning shots location (b) Recording unit (c) Moving to next location (d) Fixed receiver geometry for MASW survey.

correlation gathers of MASW data are generated. This technique furnishes much better estimation and accuracy of phase-velocity curves. Data acquisition procedure for this technique is identical to acquisition of seismic refraction data. The CMP gathers are generated after calculation for cross correlation of the original waveform [32]. Figure 5(a) is example of shot gather acquired in the field. The basic scheme applied in this current study to generate CCCMP gathers is as follows: First, in each shot record, cross-correlation of each pair of traces is carried out. Second, correlation traces with identical CMPs are collected, and then traces with equal spacing are stacked in time domain. The resultant cross correlated gathers are referred as CMP cross-correlation gathers (Figure 5(b)). The Phase velocity dispersion plots from CMP cross correlation gathers are generated by applying multi-channel analysis (Figure 5(c)). Finally the genetic algorithm is utilized to obtain inversion of dispersion curves.

\subsection{Genetic Algorithm}

Genetic Algorithms (GA) are these days well known for geophysical data inversion. The GA philosophy is fast, exact, stable, and has numerous favorable circumstances over the other ordinary procedures [33]. The genetic algorithm is based on Darwin's theory of evolution, in which likely solution is achieved [34]. The GA uses selection, crossover and mutation, the three fundamental operators of biological evolution process [35]. Geophysical parameters analogous to biological operators are wave speed, subsurface layer's thicknesses and the densities 


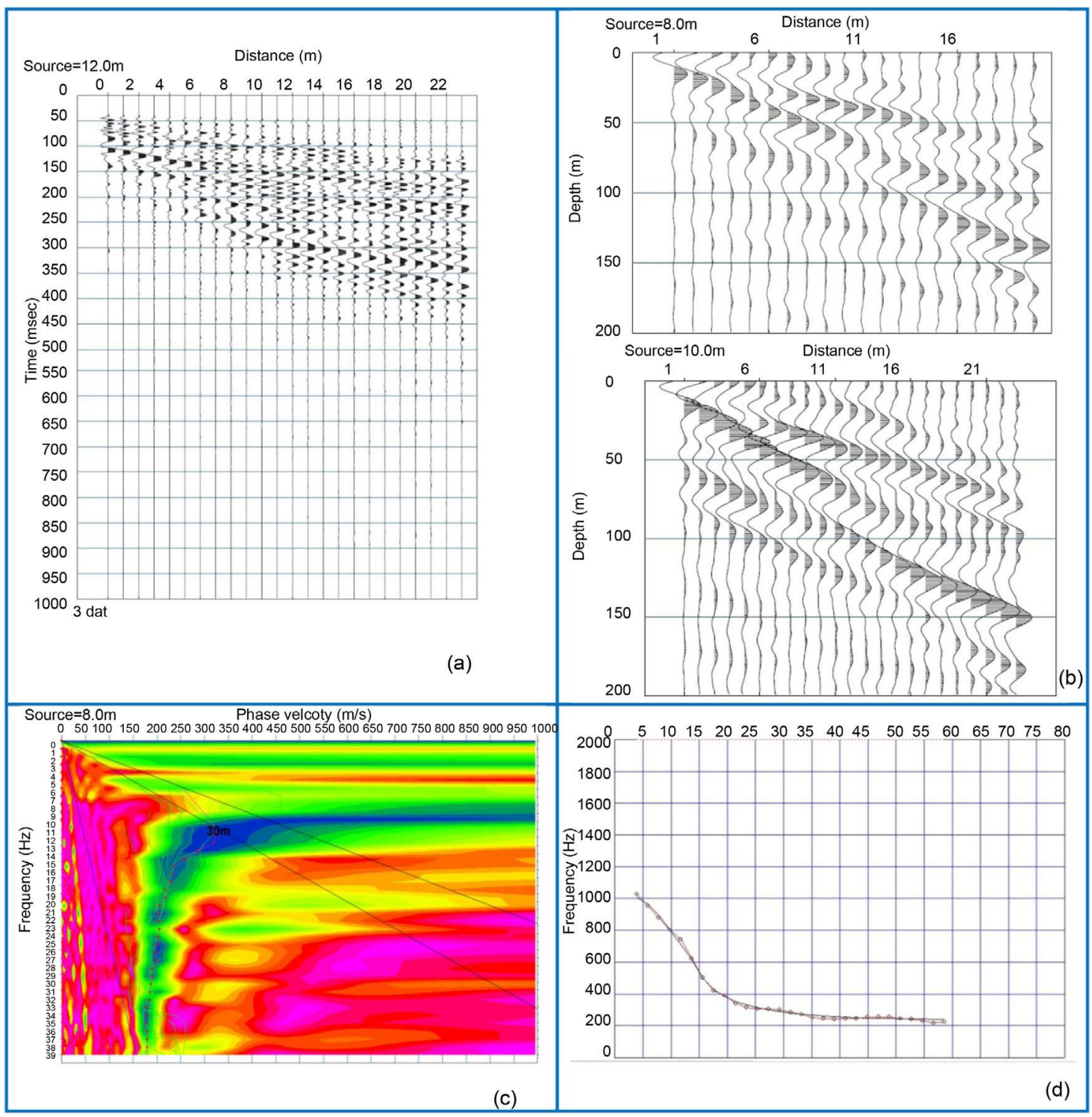

Figure 5. (a) Example of raw MASW data acquired in the field; (b) Cross Correlated CMP record generated; (c) Example of Phase velocity dispersion plots from CMP cross corraelation gathers; (d) Example analysis of observed MASW of showing best fit for phase velcoty curve by GA.

of these layers. The relative confidence on the inversion procedure can be altogether expanded for GA by utilizing most suitable initial input model [30]. Many scientist successfully applied GA effectively for inversion operations in geophysical Methods e.g., [36] [37]. The surface wave inversion carried out by GA calculation requires the minimum information [29]. The procedure is steady and exact, having different points of interest judged next to conventional methodologies. The best fits for calculated and observed dispersion curve is provided by genetic algorithm (Figure 5). The dispersion curves inversion is carried out to obtain 1D shear wave velocity profile. The shear wave's velocity is presented by averaging the inverted dispersion curves velocity profiles at the center of MASW profile (Figure 6). 


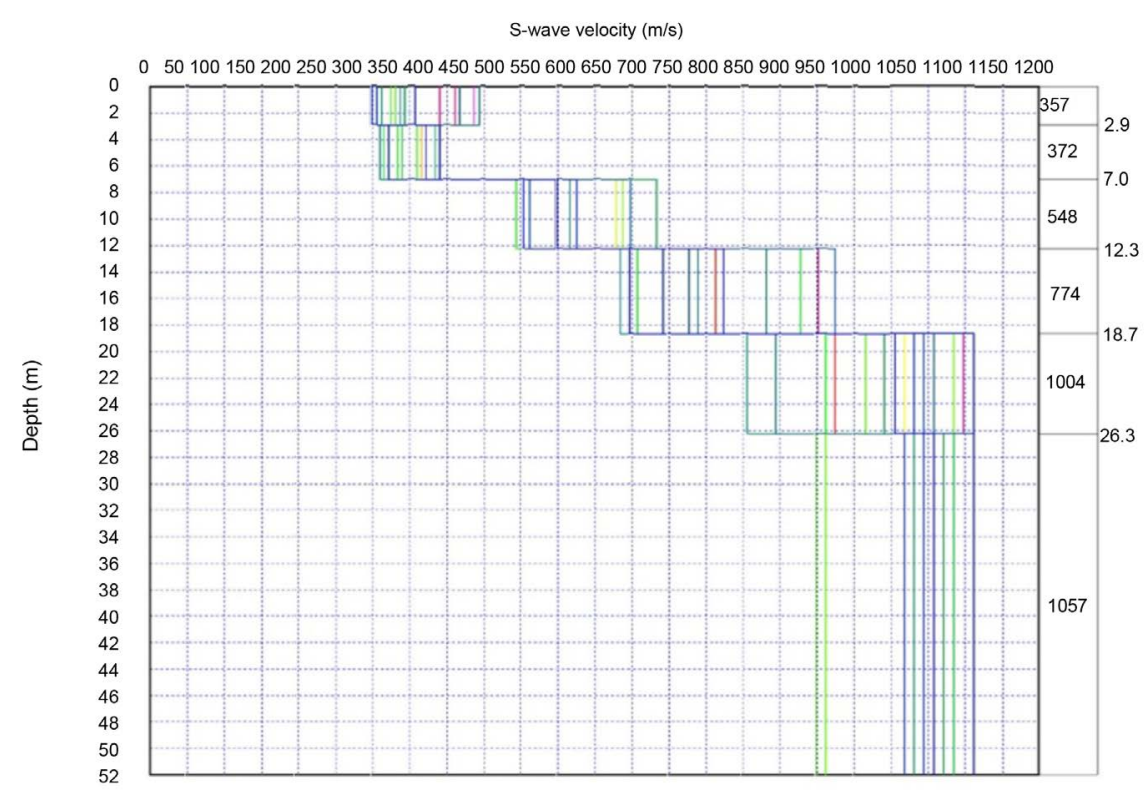

Figure 6. Shear waves profile in subsurface (32).

\section{Discussion and Conclusion}

The MASW data were acquired in Wadi Fatima, Jeddah, Saudi Arabia. Total 24 MASW profiles were acquired. CMP cross-correlated gather was generated and 1D shear wave velocities were obtained. Each profile was processed through CMP gathers generation, stacking of CMP gathers, generation of dispersion curves and finally by inverting those to obtain a $1 \mathrm{D}$ shear wave velocity model. Finally averaging was carried out for each velocity model obtained by inversion dispersion curves. The average velocity (1D) profile was assumed to the representative velocity at the center of each MASW profile obtained CMP stacks. The data acquisition with fixed receiver and multi-offset geometry reliably worked well in fluvial sediments. This technique provides a quicker way to acquire data in less accessible areas.

\section{References}

[1] Rehman, F., El-Hady, S.M., Atef, A. and Harbi, H.M. (2016) Probabilistic Seismic Hazard Assessment Methodology and Site Response Analysis Application to Seismic Microzonation. Science International (Lahore), 28, 2593-2606.

[2] Reynolds, J.M. (2011) An Introduction to Applied and Environmental Geophysics. John Wiley \& Sons, Hoboken.

[3] Anbazhagan, P. and Sitharam, T. (2009) Spatial Variability of the Depth of Weathered and Engineering Bedrock Using Multichannel Analysis of Surface Wave Method. Pure and Applied Geophysics, 166, 409-428. https://doi.org/10.1007/s00024-009-0450-0

[4] Miller, R.D., Xia, J., Park, C.B. and Ivanov, J.M. (1999) Multichannel Analysis of Surface Waves to Map Bedrock. The Leading Edge, 18, 1392-1396. https://doi.org/10.1190/1.1438226

[5] Mahajan, A., Slob, S., Ranjan, R., Sporry, R. and van Westen, C.J. (2007) Seismic 
Microzonation of Dehradun City Using Geophysical and Geotechnical Characteristics in the Upper $30 \mathrm{~m}$ of Soil Column. Journal of Seismology, 11, 355-370. https://doi.org/10.1007/s10950-007-9055-1

[6] Bajaj, K. and Anbazhagan, P. (2017) Combined Active and Passive Multi-Channel Analysis of Surface Waves for Site Characterization of Indo-Gangetic Basin, India. In: Symposium on the Application of Geophysics to Engineering and Environmental Problems 2017, Society of Exploration Geophysicists and Environment and Engineering Geophysical Society, 365-365. https://doi.org/10.4133/SAGEEP.30-045

[7] Mi, B., Xia, J., Shen, C., Wang, L., Hu, Y. and Cheng, F. (2017) Horizontal Resolution of Multichannel Analysis of Surface Waves. Geophysics, 82, EN51-EN66. https://doi.org/10.1190/geo2016-0202.1

[8] Karsl1, H., Şenkaya, G.V., Şenkaya, M. and Güney, R. (2017) Investigation of Soil Structure in Uzungöl Settlement Area by Shallow Seismic Methods. Eurasian Journal of Soil Science, 6, 134-143. https://doi.org/10.18393/ejss.286548

[9] Pamuk, E., Akgün, M., Özdağ, Ö.C. and Şahin, E. (2016) İzmir Körfezi Doğusunun Sı̆̆ Kayma Dalgası Hız Yapısının 2B’lu Çok Kanallı Yüzey Dalgası Analizi (ÇKYD) Yöntemiyle Araştırılması. Bitlis Eren Üniversitesi Fen Bilimleri Dergisi, 5.

[10] Xia, J., Miller, R.D., Park, C.B. and Ivanov, J. (2000) Construction of 2-D Vertical Shear Wave Velocity Field by the Multichannel Analysis of Surface Wave Technique. In Proceedings of the Symposium on the Application of Geophysics to Engineering and Environmental Problems, Arlington, 20-24.

[11] Mahdavi, M. and Siahkoohi, H.R. (2009) Multi-Channel Analysis of Surface Waves Using Common Midpoint Cross Correlation Method.

[12] Rehman, F., El-Hady, S.M., Atef, A.H. and Harbi, H.M. (2016) Multichannel Analysis of Surface Waves (MASW) for Seismic Site Characterization Using 2D Genetic Algorithm at Bahrah Area, Wadi Fatima, Saudi Arabia. Arabian Journal of Geosciences, 9, 1-13. https://doi.org/10.1007/s12517-016-2544-1

[13] Yagi, Y. and Kamal, H. (2016) Implementation of Integrated Multi-Channel Analysis of Surface Waves and Waveform Inversion Techniques for Seismic Hazard Estimation. Arabian Journal of Geosciences, 9, 1-16.

[14] Park, C.B., Miller, R.D. and Xia, J. (1998) Imaging Dispersion Curves of Surface Waves on Multi-Channel Record. SEG Technical Program Expanded Abstracts 1998, 1377-1380. https://doi.org/10.1190/1.1820161

[15] Båth, M. (1975) Introduction to Seismology. Geophysical Journal of the Royal Astronomical Society, 40, 143-143.

[16] Stokoe, K.H., Wright, S., Bay, J. and Roesset, J. (1994) Characterization of Geotechnical Sites by SASW Method. In: Woods, R.D., Ed., Geophysical Characterization of Sites, ISSMFE Technical Committee, Oxford, 15-25.

[17] Xu, Y., Xia, J. and Miller, R.D. (2006) Quantitative Estimation of Minimum Offset for Multichannel Surface-Wave Survey with Actively Exciting Source. Journal of Applied Geophysics, 59, 117-125. https://doi.org/10.1016/j.jappgeo.2005.08.002

[18] Hamimi, Z., Matsah, M., El-Shafei, M., El-Fakharani, A., Shujoon, A. and Al-Gabali, M. (2012) Wadi Fatima Thin-Skinned Foreland FAT Belt: A Post Amalgamation Marine Basin in the Arabian Shield. Open Journal of Geology, 2, 271. https://doi.org/10.4236/ojg.2012.24027

[19] Moore, T.A. and Al-Rehaili, M.H. (1989) Geologic Map of Makkah Quadrangle, Sheet 21D, Kingdom of Saudi Arabia: DGMR. Geoscience Map GM-107C, $1(250,000)$. 
[20] Johnson, P.R., Andresen, A., Collins, A.S., Fowler, A.R., Fritz, H., Ghebreab, W. and Stern, R.J. (2011) Late Cryogenian-Ediacaran History of the Arabian-Nubian Shield: A Review of Depositional, Plutonic, Structural, and Tectonic Events in the Closing Stages of the Northern East African Orogen. Journal of African Earth Sciences, 61, 167-232. https://doi.org/10.1016/j.jafrearsci.2011.07.003

[21] Shanti, A.M. (2009) Geology of the Arabian Shield of Saudi Arabia. Scientific Publishing Centre, King Abdulaziz University, Jeddah.

[22] Brom, A. and Stan-Kłeczek, I. (2015) Comparison of Seismic Sources for Shallow Seismic: Sledgehammer and Pyrotechnics. Contemporary Trends in Geoscience, 4, 39-45. https://doi.org/10.1515/ctg-2015-0004

[23] Lane Jr., J.W., Ivanov, J., Day-Lewis, F.D., Clemens, D., Patev, R. and Miller, R.D. (2008) Levee Evaluation using MASW: Preliminary Findings from the Citrus Lakefront Levee, New Orleans, Louisiana. In: Symposium on the Application of Geophysics to Engineering and Environmental Problems, Society of Exploration Geophysicists, 703-712.

[24] Hayashi, K. and Suzuki, H. (2004) CMP Cross-Correlation Analysis of Multi-Channel Surface-Wave Data. Exploration Geophysics, 35, 7-13.

https://doi.org/10.1071/EG04007

[25] Hayashi, K. and Hikima, K. (2003) CMP Analysis of Multi-Channel Surface Wave Data and Its Application to Near-Surface S-Wave Velocity Delineation. In: Symposium on the Application of Geophysics to Engineering and Environmental Problems, Society of Exploration Geophysicists, 1348-1355.

[26] Askari, R., DeMeersman, K. and Ferguson, R.J. (2012) Estimation of Near Surface Shear Wave Velocity using CMP Cross-Correlation of Surface Waves (CCSW). In: 2012 SEG Annual Meeting, Society of Exploration Geophysicists, 1-15. https://doi.org/10.1190/segam2012-1363.1

[27] Samyn, K., Bitri, A. and Grandjean, G. (2013) Imaging a Near-Surface Feature using Cross-Correlation Analysis of Multi-Channel Surface Wave Data. Near Surface Geophysics, 11, 1-10. https://doi.org/10.3997/1873-0604.2012007

[28] Dal Moro, G., Pipan, M., Forte, E. and Finetti, I. (2003) Determination of Rayleigh Wave Dispersion Curves for Near Surface Applications in Unconsolidated Sediments. In: 2003 SEG Annual Meeting, Society of Exploration Geophysicists, 1247-1250. https://doi.org/10.1190/1.1817508

[29] Dal Moro, G., Pipan, M. and Gabrielli, P. (2007) Rayleigh Wave Dispersion Curve Inversion via Genetic Algorithms and Marginal Posterior Probability Density Estimation. Journal of Applied Geophysics, 61, 39-55.

https://doi.org/10.1016/j.jappgeo.2006.04.002

[30] Kanlı, A.I., Tildy, P., Prónay, Z., Pınar, A. and Hermann, L. (2006) VS 30 Mapping and Soil Classification for Seismic site Effect Evaluation in Dinar Region, SW Turkey. Geophysical Journal International, 165, 223-235. https://doi.org/10.1111/j.1365-246X.2006.02882.x

[31] Miller, R.D., Park, C.B., Ivanov, J.M., Xia, J., Laflen, D.R., Gratton, C. and Overton, R. (2000) MASW to Investigate Anomalous Near-Surface Materials at the Indian Refinery in Lawrenceville, Illinois. Kansas Geol. Surv. Open-File Rept, 4.

[32] Rehman, F. (2016) Assessment of Seismic Hazard by Microzonation in Bahra Area, Wadi Fatima, Kingdom of Saudi Arabia. King Abdulaziz University, Jeddah.

[33] Pezeshk, S. and Zarrabi, M. (2005) A New Inversion Procedure for Spectral Analysis of Surface Waves using a Genetic Algorithm. Bulletin of the Seismological Society of America, 95, 1801-1808. https://doi.org/10.1785/0120040144 
[34] Vose, M.D. (1999) The Simple Genetic Algorithm: Foundations and Theory. MIT Press, Cambridge.

[35] Boschetti, F. and Moresi, L. (2001) Interactive Inversion in Geosciences. Geophysics, 66, 1226-1234. https://doi.org/10.1190/1.1487069

[36] Boschetti, F., Dentith, M.C. and List, R.D. (1996) Inversion of Seismic Refraction Data using Genetic Algorithms. Geophysics, 61, 1715-1727. https://doi.org/10.1190/1.1444089

[37] Qiu, N., Liu, Q.-S., Gao, Q.-Y. and Zeng, Q.-L. (2010) Combining Genetic Algorithm and Generalized Least Squares for Geophysical Potential Field Data Optimized Inversion. IEEE Geoscience and Remote Sensing Letters, 7, 660-664. https://doi.org/10.1109/LGRS.2010.2045152 